\title{
MANAGEMENT APPROACH BETWEEN BUSINESS CLUSTER SUCCESS AND SOFT LEADER CHARACTERISTICS
}

\author{
Robert Lippert, Zoltan Gaál \\ University of Pannonia, Veszprém, Hungary \\ E-mail: robert.lippert@alapeuropa.com,gaal@gtk.uni-pannon.hu
}

\begin{abstract}
One of the potential aspects of economic growth lies in focusing on furtherance the development of business clusters. By linking the complementary competencies of profit oriented enterprises, $N G O-s$, universities, research institutes and local authorities, the innovation potential and the productivity are significantly increased. The present study investigates a specific and challenging managerial activity, the role of the cluster manager. The aim of the research is to reveal the intrinsic motivation of cluster operations and to demonstrate the importance of the manager in the efficient and sustainable operation. An empirical research has been conducted involving cluster managers and member organisations through an extensive questionnaire survey in Hungary. First, determinant factors of cluster success have been identified. By using these factors, as the operational activity of the cluster, as well as the satisfaction of the members in the field of innovation and productivity, a new continuous three-dimensional maturity model has been introduced to evaluate the cluster success. Mapping the soft factors, organisational culture and leadership roles have been assessed by applying Competing Values Framework method. The results of the research depict the correlation found between soft leader characteristics and cluster success.
\end{abstract}

Key words: cluster, leadership roles, organisational culture, success.

\section{Introduction}

Business clusters have been defined by various authors in several different ways (Porter, 1998; Enright, 1996; Bergman \& Feser, 1999, Rosenfeld, 2000). There is one aspect the relevant studies have in common. They place the focus on a natural economic process and aim to give a detailed description of their findings. Economic features differ geographically, but from the second half of the 20th century it is also dynamically changing because of the constantly accelerating economic development.

The analysis of the observed processes resulted in defining the cluster development as a method of economic growth $(O E C D, 2005)$, as well as a useful and efficient instrument. As a result the process has been reversed. Recognising the advantages, the primarily evolutional process of clustering was accompanied by a deliberate endeavour, where competent and conscious leadership gains central importance (Sölvell, Ketels \& Lindquist, 2003). It is particularly verified in economic environments where the lack of means and time hindered the progress of the natural processes. Even under such conditions there are functioning clusters which, however, differ in various significant aspects from the natural economic evolution of clustering. 
PROBLEMS

OF MANAGEMENT

IN THE $21^{\text {st }}$ CENTURY Vol. 9, No. 1, 2014

28

Methodology of Research

\section{General Background of Research}

The research questions have been compiled based on three consecutive aspects. Firstly, our general enquiries refers to the present state of clustering. Primary and secondary resources published by relevant professional literature and deed of foundation disclosed by the clusters have been collected and analysed. It was followed by the conduct of structured interviews with cluster managers and the evaluation of the findings of the questionnaire-based survey. The remaining questions of our investigation are of methodological and empirical nature.

A methodological issue is how cluster operations can be described and whether it is possible to create an assessment tool to define cluster success. The empirical questions aim to demonstrate the correlation between the created cluster success measurement system and the soft characteristic features of the manager. It also attempts to justify the role of the organisational culture, the management roles and the preferred managerial goals in the successful operation.

The research model (Figure 1.) has been set up and systematically utilised in order to gain answers on specific questions.

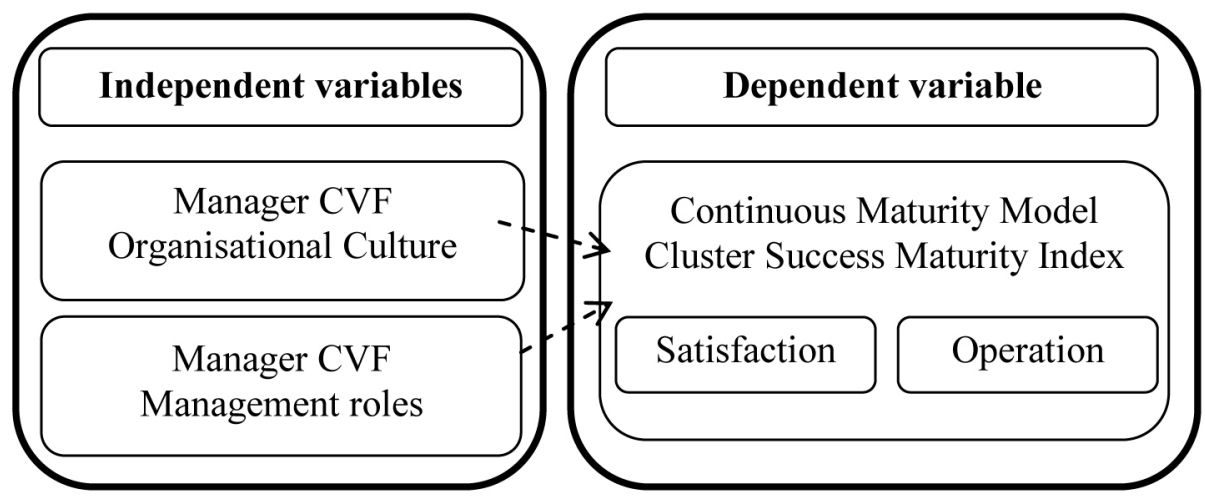

Figure 1: Research model.

Member satisfaction and a constant and appropriate activity reflect the success of a business cluster. By defining the determinant factors to describe satisfaction and applying the continuous maturity model, a Cluster Success Maturity Index can be calculated for each participant of the study.

As a second step of creating the model indicators were searched which can influence the managerial performance. Here, the connection between the single maturity levels and the soft leadership characteristics are of utmost importance. According to Quinn's Competing Values Framework (CVF) there are no positive or negative features to be distinguished (Cameron \& Quinn, 2011). Each element of a culture and each single management role with its competences (Quinn, Faerman, Thompson \& McGrath, 2003) are essential in successful leadership. Our basic aim is to find a combination of attributes which make a manager capable of leading the organisation. The tasks of the cluster manager, the diversity of the members and the large scope of activities suggest that a cluster manager should, at least at the level of empathy, be suitable for the application of several ways of thinking. Finally, we were searching for correlations between the Cluster Success Measurement Index and soft manager roles. 


\section{Sample of Research}

In the conduction of the survey all the clusters with availability have been contacted. Out of 216 addressed clusters 115 business clusters have responded to the questionnaire. The received 98 managerial questionnaire means an over $45 \%$ query. In the case of the members the size of the sample can only be determined by estimation. We have received altogether 486 member questionnaires which means more than $10 \%$ response rate of the whole sample. To limitate the findings it has to be mentioned that the questionnaires were filled in by managers and members which implement an active and conscious operation. The analysed database consists of 396 elements, each of them including the data of the member, its cluster and also its cluster manager.

\section{Instrument and Procedures}

The questionnaire-based quantitative survey was carried out involving business clusters and managers representing all regions in Hungary in the second half of 2012. Beforehand, personal structural interviews had been conducted with 10 cluster managers. These interviews assisted as a qualitative method in the formation of the questionnaire as well as in the evaluation of the findings. By analysing cluster operation activity the main target was to present to what extent cluster development collides with the theory. Similar to Altman's model (Altman, Marco \& Varetto, 1994), several indicators have been aggregated to a single variable defining cluster operation. The progress is indicated by the presence of inter-firm cooperation before the foundation, the age of the business cluster and the change in the number of its members. The number of the corporate activity reflects the intensity of the cooperation. An important indicator in connection with sustainable and effective development is whether the organisation has a written strategy, and whether there have been any significant transformations since the formation of the business cluster.

\section{Data Analysis}

\section{Dependent variable: Cluster Success Maturity Index}

The continuous maturity model has been formed with the help of member satisfaction and cluster operation activity. A methodological criteria were, that the variables should be binned in the same quantity of categories and that they should be independent from each other. The satisfactory components are produced by factor analysis and are independent due to the procedure. The independence of the dimensions of operation and satisfaction has been proved via cross-tabulation method.

By satisfaction measurement, to be able to the analyse the latent structures behind the responses and to decrease the dimensions the Principal Component method $(\mathrm{KMO}=0.953)$ with Varimax rotation and Kaiser normalisation has been used. The two main components present $68,009 \%$ preservation of the original variance.

The determinant factors included in the maturity model are as follows:

- Benefits serving productivity, efficiency and economical operation

- Advantages related to innovation, R\&D opportunities and development

- Cluster operation activity

Independent variable: Cluster manager CVF features

The Competing Values Framework evaluates organisations along two dimensions. The 
Robert LIPPERT, Zoltan GAÁL. Management Approach between Business Cluster Success and Soft Leader Characteristics

PROBLEMS

OF MANAGEMENT

IN THE $21^{\text {st }}$ CENTURY Vol. 9, No. 1, 2014

axes divide the plane into four quadrants, which define four management models. The Open Systems Model, The Rational Goal Model, The Internal Process Model and the Human Relations Model are presented in Figure 2.

One of the axes stretches between Flexibility and Control and depicts the adaptation to changes, whether the given organisation reacts quickly and flexible or prefers the application of control and bureaucracy. The other axis connects Internal and External focus which marks whether the organisation concentrates outwards on its environment or rather on inner processes.

Each quadrant is characterised by one organisational culture profile. Analysing culture, the research is extended to six set of issues: main organisational features, organisational management, management style, cohesion, strategical emphasis and success criteria. The single fields of culture are defined by four statements in each set. The participants have to distribute 100 points for the statements to demonstrate how valid they are for their organisation.

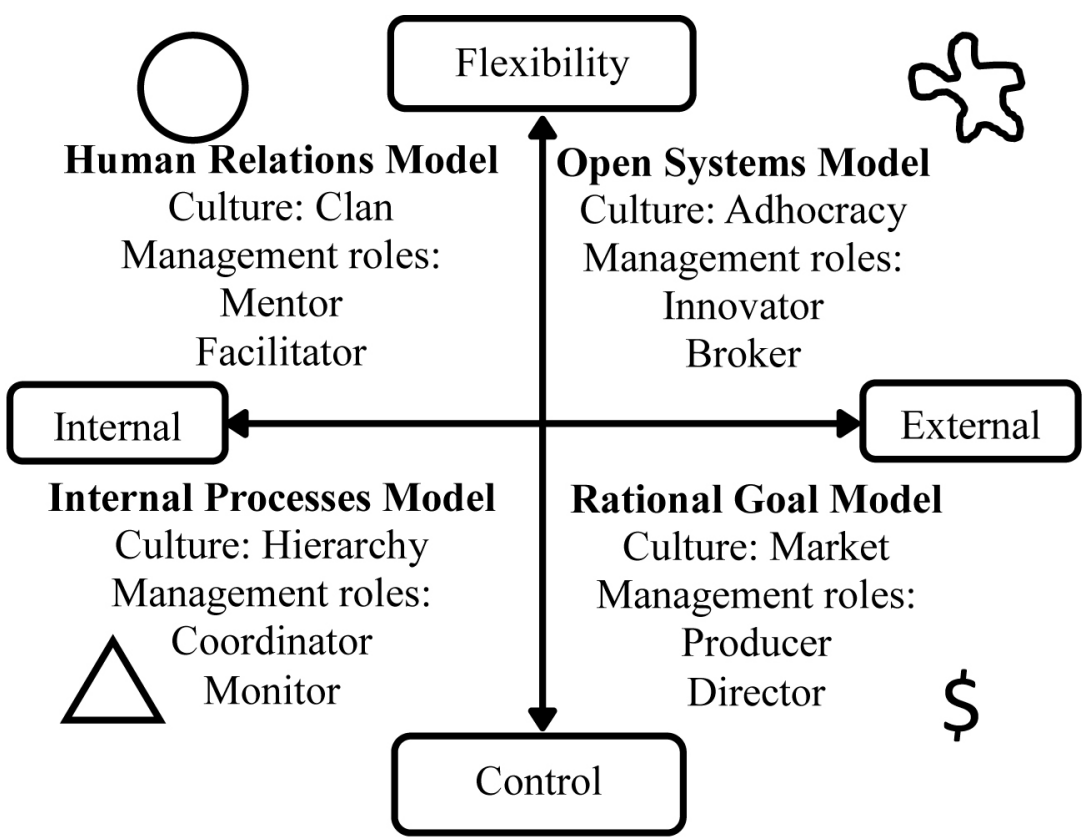

Source: Quinn, 1988

\section{Figure 2: The Competing Values Framework.}

From the various approaches describing culture this model gives the opportunity to map not only present, but preferred culture as well and it provides additional information relating to the strategic orientation of the participants. Clusters are not founded to settle one single project; strategical thinking, long-term planning and the existance of a vision is substantial for a permanent and sustainable operation. (Szabó \& Csepregi, 2009) When it comes to the change of external circumstances, organisational culture obtains capital importance. As far as management roles are concerned altogether eight different profiles, two per quadrant, are distinguished. Each management role includes three management competencies. The application of the model enables the analysis of the competencies in more detail. Similarly to the culture here also lies the opportunity to evaluate strategical thinking. 


\section{Results of Research}

To analyse the link between the dominant organisational culture and the maturity index presenting cluster success variance analysis is used. Running the ANOVA test the F probe showed a significant connection (Table 1.). This fact proves only the existence of a connection, the details can be detected via Post-Hoc analysis.

Table 1. ANOVA test Cluster Success Maturity Index vs. Dominant organisational culture.

\begin{tabular}{llllll}
\hline \multicolumn{5}{c}{ ANOVA } \\
\hline & Sum of Squares & df & Mean Square & F & p \\
\hline Between Groups & 1,031 & 3 & 0.344 & 3.075 & 0.028 \\
\hline Within Groups & 39,350 & 352 & 0.112 & & \\
\hline Total & 40,381 & 355 & & & \\
\hline
\end{tabular}

Since the Levene test did not present any significant results, the sample fulfils the requirement of homogeneity. Therefore, LSD statistics have been applied.

According to the results, the maturity index of Adhocracy and Market is remarkably higher than those of the Hierarchy or Clan. In the Competing Values model both positively effected cultures can be found on the open side of the Internal and External focus axis. Only one dominant culture showed a significant outcome. Consequently, it can be stated that the higher maturity index serves an open, but structured way of thinking, the Market organisational culture. Market culture belongs to the management model of Rational Goal. It is a result oriented organisation that emphasises the appropriate solution of tasks. Its stakeholders are competitive and target-oriented. The managers are heavy-handed with high expectations. They consider success, victory, win and fame the most important. The basis of the organisational style is the competition. To improve quality they apply the survey of customer needs, the development of productivity and the improvement of external relations. Cluster success is also supported by Adhocracy culture, which is characteristic for the Open System management model. Adhocracy means a dynamic and creative environment. The stakeholders are ready to take risks and so are the leaders, who often have innovative ideas. Experimentation and innovation are strong cohesive devices within the organisation. Their long-term goals are expansion and the acquisition of new resources. The introduction of new products or services is considered as success. They support individual initiative and open thinking.

By the investigation of the effects of management roles the F probe of the ANOVA test indicates a strong connection between the dominant management roles and the maturity index (Table 2.) 
Robert LIPPERT, Zoltan GAÁL. Management Approach between Business Cluster Success and Soft Leader Characteristics

PROBLEMS

OF MANAGEMENT

IN THE $21^{\text {st }}$ CENTURY Vol. 9, No. 1, 2014

Table 2. ANOVA test Cluster Success Maturity Index vs. Dominant management role.

\begin{tabular}{llllll}
\hline \multicolumn{7}{c}{ ANOVA } \\
\hline & Sum of Squares & df & Mean Square & F & p \\
\hline Between Groups & 6,051 & 7 & 0.864 & 8.782 & 0.000 \\
\hline Within Groups & 34,645 & 352 & 0.098 & & \\
\hline Total & 40,695 & 359 & & \\
\hline
\end{tabular}

According to the Kolmogorov-Smirnov test due to the large number of dimensions the requirement of homogeneity is not fulfilled. Consequently, during the Past-Hoc analysis the Tamhane's method has been applied.

The results depict a significant difference in the Mentor management role. A Mentor manager is understanding, empathic, pays attention to others and is aware of individual needs. This type of leader can be described by mutual respect and trust. Moral and commitment are crucial for him. The Facilitator belongs to the same quadrant, but its influence is entirely the opposite.

This kind of manager seeks agreement and consensus and makes other people take part in problem-solving and decision-making. This sort of leader is characterised by breadth of view and considers community and teamwork essential. According to the results the Mentor assists the achievement of a higher maturity index while the Facilitator hinders it owing to its permissive attitude. The Innovator role has a positive impact, which differs significantly from the Director and Facilitator roles. The Innovator is smart and creative, in favour of changes continuously promoting them. This type of leader is an innovator and has a flexible personality.

He foresees the future and can hold the expectation for a prosperous one in others. Coordinator and Monitor roles foster cluster success to a lesser degree. The Monitor is a technically skilled, well-informed leader. He is aware of the cluster operations, supervises them, controls the observation of rules and efficiency. This type of leader formulates detailed documentations, is able to evaluate data well and is in possession of excellent problem-solving skills. The Coordinator is good at recognising situations, is a reliable manager and sustains the order and continuity of the operations. This sort of manager organises and coordinates actions, complies and assesses written reports and coordinates planning.

\section{Discussion}

Effective cluster operation is predominantly characterised by the display of geographical, economic, and, possibly, employment data. The most comprehensive surveys so far as "The Cluster Initiative Greenbook" (Sölvell et al., 2003) also followed this line of thought. In recent years, several best practice, labelling, and cluster excellence programs have been started which focus on the cluster initiatives. However, the applied selection mechanisms often follow national priorities or politically driven objectives. ("European cluster excellence initiative", 2012) The field of quality characteristics of management is a less researched area; therefore no complex, verified procedure has been drafted to assess successful collaboration.

During the research a new three-dimensional continuous maturity model has been set up in integration with the industry-driven and knowledge-driven satisfaction of the members and the operation activity of the clusters. The maturity index defined the management based cluster success and the relation between the soft management roles and cluster success has been 
explored. It has been verified that the manager, the culture according to the Competing Values Framework and the features of management roles can influence cluster success. This success is furthered by Market organisational culture and Adhocracy but is least supported by Hierarchy. Mentor and Innovator management roles effect success positively and is also assisted by Coordinator and Monitor. As the results present, the managers belonging to the category of Director and Facilitator management roles lead, less successful business clusters.

The research has confirmed that cluster success is influenced by the model the leader represents and proves the existence of a culture and management role profile which furthers the operation. The qualitative, soft features of the cluster manager are highlighted overstepping the traditional economic and social network.

\section{Conclusions}

In case of clusters the most frequently emphasised phenomenon is the competitive cooperation. This philosophy is closely connected to the theory of clustering and its regular operation especially when not only the financially measurable hard aspects of business prospects but also the soft aspects of its role in the community, prestige, honour, and reliance are taken into consideration. From that approach, competition is detectable and serves as a driving force within a relatively closed community, even though they are no direct competitors on the market.

The conscious managerial behaviour is critical in order to understand the diversity of its members, the individual attitude of the participants which alter in basic aspects of economy, size, age and activity field. Also, they differ in internal, soft, cultural and managerial characteristics.

Our investigation revealed that the management roles are worth to understand and improve with regard to long-term and sustainable cluster operation. The result-oriented, purposeful environment and the supportive, open and innovative attitude of the manager assist the successful establishment and sustainable operation of a business cluster.

\section{References}

Altman, E. I., Marco, G., \& Varetto, F. (1994). Corporate distress diagnosis: Comparisons using linear discriminant analysis and neutral network (the Italian experience). Journal of Banking and Finance, 18 (3), 505-529. doi:10.1016/0378-4266(94)90007-8.

Bergman, E. M., Feser, E. J. (1999). Industry clusters: A methodology and framework for regional development policy in the United States. In OECD, Boosting innovation: The cluster approach (pp. 243-268). Paris: OECD Publications.

Cameron, K. S., \& Quinn, R. E. (2011). Diagnosing and changing organizational culture: Based on the competing values framework (3th Ed.). San Francisco, CA: Jossey-Bass.

Enright, M. J. (1996). Regional clusters and economic development: A research agenda. In U. H. Staber, N. V. Schaefer, \& B. Sharma (Eds.), Business networks: Prospect for regional development (pp. 190-213). Berlin: Walter de Gruyter.

European cluster excellence initiative (ECEI): The quality label for cluster organisations - criteria, processes, framework of implementation. (2012). Retrieved February 24, 2014, from http://www. cluster-excellence.eu/fileadmin/_cluster-excellence/downloads/GOLD-Assessment.pdf

OECD. (2005). Business clusters: promoting enterprise in Central and Eastern Europe. Available from http://www.oecd.org/cfe/leed/businessclusterspromotingenterpriseincentralandeasterneurope.htm Porter, M. E. (1998). On competition. Boston, MA: Harvard Business School Publishing.

Quinn, R. E., Faerman, S. R., Thompson, M. P., \& McGrath, M. R. (2003). Becoming a master manager: a competency framework (3rd Ed.). New York, NY: John Wiley \& Sons.

Quinn, R. E. (1988). Beyond rational management: mastering the paradoxes and competing demands of high performance. San Francisco, CA: Jossey-Bass. 
Robert LIPPERT, Zoltan GAÁL. Management Approach between Business Cluster Success and Soft Leader Characteristics

PROBLEMS

OF MANAGEMENT

IN THE $21^{\text {st }}$ CENTURY Vol. 9, No. 1, 2014

34

Rosenfeld, S. A., (2000). Community college / cluster connections: Specialisation and competitiveness in the United States and Europe. Economic Development Quarterly, 14 (1), 51-62. doi: $10.1177 / 089124240001400107$

Sölvell, Ö., Ketels, C., \& Lindquist, G. (2003). The cluster initiative Greenbook. Retrieved from http:// www.isc.hbs.edu/pdf/Greenbook.pdf

Szabó, L., \& Csepregi, A. (2009). A válság hatása a szervezeti kultúra alakulására - jó irányba haladunk? Harvard Business Review, 11 (11), 29-34.

Advised by Cizmadia Tibor, Pannonia University, Veszprém, Hungary

Received: January 31, 2014

Accepted: April 05, 2014

Robert Lippert PhD Candidate, Doctoral School of Management Sciences and Business Administration, University of Pannonia, Állvány u. 7., H-8200, Veszprém, Hungary.

E-mail: robert.lippert@alapeuropa.com

Zoltan Gaál $\quad$ PhD., Professor, University of Pannonia, Egyetem u. 10., H-8200, Veszprém, Hungary.

E-mail: gaal@gtk.uni-pannon.hu 